\title{
Mosquitoes and the Lymphatic Filarial Parasites: Research Trends and Budding Roadmaps to Future Disease Eradication
}

\author{
Damilare O. Famakinde \\ Department of Medical Microbiology and Parasitology, College of Medicine of the University of Lagos, \\ Idi-Araba, Lagos 100254, Nigeria; damfam.joe@gmail.com; Tel.: +234-703-330-2069
}

Received: 18 December 2017; Accepted: 27 December 2017; Published: 4 January 2018

\begin{abstract}
The mosquito-borne lymphatic filariasis (LF) is a parasitic, neglected tropical disease that imposes an unbearable human scourge. Despite the unprecedented efforts in mass drug administration (MDA) and morbidity management, achieving the global LF elimination slated for the year 2020 has been thwarted by limited MDA coverage and ineffectiveness in the chemotherapeutic intervention. Moreover, successful and sustainable elimination of mosquito-vectored diseases is often encumbered by reintroduction and resurgence emanating from human residual or new infections being widely disseminated by the vectors even when chemotherapy proves effective, but especially in the absence of effective vaccines. This created impetus for strengthening the current defective mosquito control approach, and profound research in vector-pathogen systems and vector biology has been pushing the boundaries of ideas towards developing refined vector-harnessed control strategies. Eventual implementation of these emerging concepts will offer a synergistic approach that will not only accelerate LF elimination, but also augurs well for its future eradication. This brief review focuses on advances in mosquito-filaria research and considers the emerging prospects for future eradication of LF.
\end{abstract}

Keywords: mosquitoes; filarial parasites; vector-parasite system; lymphatic filariasis; eradication

\section{Introduction}

Mosquitoes are unambiguously the most important vectors of infectious disease-causing agents that tremendously affect global health, with over half of the global human population at risk of exposure to mosquito-transmitted infections [1] and more than 1 billion cases of such infections reported each year [2]. Brugia malayi (Brugia), Brugia timori (Partono et al.), and, most importantly, Wuchereria bancrofti (Cobbold) are the mosquito-vectored filarial parasites causing human lymphatic filariasis (LF). They are transmitted by members of Anopheles, Culex, Aedes, Mansonia, and Ochlerotatus genera of mosquitoes, depending on the geographical location and biological peculiarities of each species [3]. Human LF is a neglected tropical disease (NTD) that presents with chronic disfiguring pathologies such as lymphoedema and elephantiasis (disfiguring swelling) of the legs, of the scrotum (hydrocoele) in males, and of the breasts and vulva in females [4], and the resulting deformities also generate severe psychosocial consequences including sexual disability [5] and mental depressive illness $[6,7]$.

To address the unbearable disease scourge, the World Health Organization (WHO) launched the Global Programme to Eliminate Lymphatic Filariasis (GPELF) in the year 2000, with a commitment towards eliminating LF as a public health problem by 2020. While the GPELF also ensures morbidity management and disability prevention (MMDP), mass drug administration (MDA) has been the mainstay of the programme and generous drug donations from world-respected pharmaceutical companies (Eisai, GlaxoSmithKline, Johnson \& Johnson, and Merck Sharp \& Dohme [MSD]), have 
been facilitating wider global coverage of the MDA $[8,9]$. Depending on location and co-endemicity, the long-adopted WHO recommendations for MDA to eliminate LF are annual albendazole administration and annual combination therapy systems (using albendazole with ivermectin or with diethylcarbamazine) for at least five effective rounds. In May 2017, modifications to the existing recommendations were formulated to optimise human responses to the MDA regimens and accelerate the pace of the disease elimination. Annual triple-drug regimen (ivermectin + diethylcarbamazine + albendazole) and biannual albendazole were included, depending on the epidemiological and technical situations [10]. At the inception of GPELF, an estimated 120 million people were infected, of whom 40 million were seriously incapacitated and disfigured by the disease [11]. However, more recent data acknowledging a 13-year impact of the GPELF extrapolated that about 67 million people are now infected: 36 million presenting clinical illness, 19 million with genital hydrocoele, and 16 million with lymphoedema [12]. Currently, LF accounts for 2 million disease-adjusted life years (DALYs) [13], not including significant co-morbidity of mental illness commonly experienced by patients and caregivers [14].

Despite all efforts, global elimination of LF slated for the year 2020 is now practically unattainable, as 22 of the current 52 endemic countries requiring MDA have not commenced MDA in all of their endemic implementation units, and the suboptimal human response to current regimens post-MDA has surfaced $[10,14,15]$. The latter may have ensued due to the drug inactivity against adult worms [16] or inter- and intra-species variations causing a differential response to chemotherapy [17]; meanwhile, we cannot afford to overlook the possible emergence of drug-resistant microfilariae (mf) [18-20]. Beyond the walls of GPELF interventions, other pertinent factors are also pulling the strings. Successful control of mosquito-borne diseases is often challenged by reintroduction and resurgence emanating from new or residual human infections that are further disseminated by the vectors, especially when effective human vaccines are lacking. Although the application of insecticides has been largely buttressing mosquito control for many decades, toxicity to humans and emergence of insecticide-resistant traits among mosquito populations have been worrisome trends, and dampen the effectiveness of other control measures. This implies that even in the face of the new MDA adjustments, there is still a need to recreate momentum for vector control, if the goal is achieving sustainable elimination that will lead to disease eradication. This review focuses on the advances in the area of mosquito-filaria research and promising vector-based research initiatives that may unclog future eradication of LF.

\section{The Mosquito-Filaria System: Past and Present Research}

The present era of intense and expanding search for new strategies to abate vector-mediated pathogen transmission has extended a gradually-increasing priority for research on the mosquito-filaria system. Mosquitoes are equipped with physiological, immunological, and structural components that can preclude the establishment of filarial parasites [21-24]. Of particular interest is how the parasites adapt to the hostile vector environment and achieve transmission. Migratory timing and mechanical crossing of vector midgut barriers [23,25], as well as ingestion of glycogen granules and mitochondria of the thoracic muscle cells of the vectors [26-28], constitute some part of the physical strategies employed by filarial parasites.

Setting aside the physical and macromolecular adaptation mechanisms, recent post-genomic approaches-transcriptome analysis and proteomic profiling-on B. malayi provide increasing opportunity to identify and interrogate genes or proteins expressed during filarial parasite life-stages, serving as important tools in understanding the molecular underpinnings of the biological nature of filarial worms. In most molecular studies, Aedes aegypti (Linnaeus) and B. malayi are aptly used as a model system because of their easy adaptability and maintenance in the research laboratory $[17,25]$. Exsheathment of the ingested $\mathrm{mf}$ within the mosquito is required for morphological transformation of the parasites into the first-stage larvae (L1), and may occur in the mosquito midgut or haemocoel [23,29]. The assessed transcriptome and proteome of $B$. malayi $\mathrm{mf}$ showed upregulated transcripts encoding 
serpin (serine protease inhibitor), endochitinases (e.g., BmCHT1), proteases (e.g., metalloprotease I, trypsin-like and cathepsin L-like proteases), and $\mathrm{Cys}_{2} \mathrm{His}_{2}\left(\mathrm{C}_{2} \mathrm{H}_{2}\right)$ domain-containing zinc finger proteins [30-32]. Serpins may play a role in host immunoregulation [33], and endochitinases, and proteases such as cathepsin, may jointly participate in the microfilarial exsheathment process [34-37], whereas $\mathrm{C}_{2} \mathrm{H}_{2}$ domain-containing zinc finger proteins serve as transcription factors [38]. A quantitative and exploratory transcriptome profiling using dual RNA-sequencing (RNA-seq) chronicled the serial expression of B. malayi transcripts, spanning microfilarial stages to the development of human-infective larvae (L3) in the mosquito vector [39] (Table 1). Major findings from the study showed that transcriptome changes mediating cuticular moulting (transcripts encoding a number of regulatory and structural components) are pulsatile and that overall transcript expression oscillates between high levels during the intermittent period between two moults but is maintained at low levels during ecdysis [39].

Table 1. Chronological RNA-seq expression profiles of Brugia malayi in Aedes aegypti.

\begin{tabular}{|c|c|c|}
\hline Period & Upregulated Genes Ontology & Parasite Activity \\
\hline Day 1-2 & $\begin{array}{l}\text { Mitochondrial ATP synthase complex, } \\
\text { glycolysis, integral to membrane, DNA } \\
\text { replication, signal peptidase complex, } \\
\text { phosphoric diester hydrolase activity }\end{array}$ & $\begin{array}{l}\text { Rearrangement and growth of } \\
\text { preexisting microfilarial structure, } \\
\text { extensive cuticular reorganisation, } \mathrm{mf} \\
\text { transforms into L1 }\end{array}$ \\
\hline Day 2-3 & $\begin{array}{l}\text { Calcium ion binding, response to stress, } \\
\text { serine-type endopeptidase inhibitor activity, } \\
\text { structural constituent of the cuticle }\end{array}$ & L1 development \\
\hline Day 3-4 & $\begin{array}{l}\text { Ion channel activity, transmembrane } \\
\text { transport, membrane, metallopeptidase } \\
\text { activity, steroid hormone receptor activity }\end{array}$ & $\begin{array}{l}\text { Middle to late L1 development: } \\
\text { numerous mitotic divisions, } \\
\text { lengthening of body, differentiation of } \\
\text { internal structures, e.g., well-defined } \\
\text { intestine }\end{array}$ \\
\hline Day 4-5 & Calcium ion binding, response to stress & First moulting into L2 \\
\hline Day 5-6 & $\begin{array}{l}\text { Serine-type endopeptidase inhibitor activity, } \\
\text { structural constituent of the cuticle, } \\
\text { metallopeptidase activity }\end{array}$ & $\begin{array}{l}\text { L2 start to feed and develop: genital } \\
\text { primordium is formed }\end{array}$ \\
\hline Day 6-7 & $\begin{array}{l}\text { Glycolysis, integral to membrane, } \\
\text { cysteine-type peptidase activity, structural } \\
\text { constituent of the cuticle, steroid hormone } \\
\text { receptor activity }\end{array}$ & $\begin{array}{l}\text { L2 feed, elongate and further develop: } \\
\text { rectum remains closed with anal plug }\end{array}$ \\
\hline Day 7-8 & $\begin{array}{l}\text { Structural constituent of the cuticle, } \\
\text { transmembrane transport, chloride transport }\end{array}$ & Second moulting into L3 \\
\hline
\end{tabular}

Adapted from [39].

Transcriptomic data on L3 from the mosquito showed upregulated expression of transcripts encoding various collagen protein family members on the cuticle, metabolic proteins, as well as proteins involved in stress resistance (e.g., dauer-enriched genes), pathogenesis, and immune resistance (e.g., serpin, cystatin, and abundant larval transcript-BmALT) and parasitisim (e.g., venom allergen-like protein-BmVAL-1) [31,32]. Those coding for the moult-mediating cathepsin L-like protease enzymes (e.g., BmCPL-1, BmCPL-4, and BmCPL-8) were also transcriptionally upregulated [31,32,36]. Generally, it is believed that the vast majority of these expressed proteins, in both $\mathrm{mf}$ and L3, are essential for establishment of the parasite infection and/or survival in the vector or in the subsequent mammalian host [31,32].

On the other hand, successful parasite transit through a vector indicates a degree of vector tolerability or susceptibility to the specific parasite, and the lack of this interspecies adaptive dialogue at the molecular or genetic level confers vector refractoriness to parasite invasion. The aim of 
manipulating susceptible phenotypes to drive refractoriness into the naturally susceptible vectors has motivated present research effort to develop particular interest in exploring the mosquito-expressed genes and gene products that confer susceptibility or refractoriness to filarial worms. Early investigators, who searched for the chromosomal regions of genes influencing Ae. aegypti susceptibility to filarial worms, found a sex-linked gene, $f^{m}$, located on chromosome 1 [40,41]. Subsequent molecular genetic linkage mapping approach using restriction fragment length polymorphism (RFLP) markers further identified two quantitative trait loci (QTL): fsb1 (corresponding to $f^{m}$ ) on chromosome 1 and an additive fsb2 on chromosome 2 [42]. Also, another QTL, idb2, which seems to influence Ae. aegypti ability to ingest $B$. malayi, was later found on chromosome 2 and is linked to the initial fsb2 [43].

Exploitation of the QTL to the causative gene(s) level has proved cumbersome, but recent exome sequencing, RNA-seq application, and an improved genetic linkage mapping using restricted-site-associated DNA (RDA) sequencing further highlighted that resistance of Ae. aegypti to $B$. malayi is driven by a single dominant sex-linked locus on chromosome 1 (corresponding to the QTL) and that this locus contains a number of known immune response genes, such as those controlling Toll, IMD, and JAK-STAT pathway activities, as well as other potential resistance-related genes [44,45]. Furthermore, studies have lent credence to early (usually within 48 hours) clearance of filarial worms by resistant mosquitoes with temporal expression of immune transcripts encoding antimicrobial peptides (cecropin and defensin) and transferrin, among others [45-47], while in susceptible mosquitoes, a filaria-induced upregulation of lipohorin and its receptor gene in the vector has been uncovered [48], an event that may facilitate parasite survival by suppressing mosquito immune responses [49-51].

The understanding of the physiological linkage between mosquito vectors and filarial parasites in relation to how the parasites cross their developmental checkpoints within the intermediate hosts has also been broadened. Transition of the ingested $\mathrm{mf}$ into L1 in mosquitoes occurs concurrently with an increased level of mosquito ecdysteroids, and this concomitant increase was also observed with initiation of L1 moulting to L2 and L2 to L3, implicating that ecdysteroid signaling is critical to the regulation of intramosquito filarial moulting [52]. Elucidating further the molecular trigger of moulting in filarial parasites, a functional B. malayi ecdysteroid receptor, Bma-EcR, was characterised [52].

\section{Emerging Prospects of Achieving LF Eradication through Implementation of Mosquito-Parasite Approaches}

Considering the vicious circle that may ensue with the current control of LF and the significant contribution from the insecticide-resistant disease-spreading vectors, knowledge of the molecular groundwork of the mosquito-filaria system and vector biology, coupled with the present technological advancement, has a great potential to translate into concrete ideas that may open wide avenues for developing new transmission-blocking or transmission-reducing strategies to combat LF more effectively. For instance, RNA interference (RNAi)-mediated silencing of the Bmcpl-1 gene utterly disrupted B. malayi motility and development into the L3 stage in Ae. aegypti [53], indicating that robust understanding of the immunological, cellular, and physiological pathways or transductions in both filarial parasites and mosquitoes during the vector-parasite interface will direct research into devising novel transmission-blocking strategies, perhaps through delivery of transmission-blocking drugs (TBD) or vaccines (TBV) into the vectors. Drugs preventing $\mathrm{mf}$ exsheathment and $\mathrm{mf}$ migration through the mosquito gut wall, as well as those targeting the intramosquito developmental larval stages (L1, L2, and L3), have been proposed as potential targets for new antifilarial TBD designs [54]. For example, drugs acting as ecdysone or Bma-EcR antagonists may successfully arrest intramosquito filarial larval development. However, a potential but possibly circumventable difficulty in developing such drugs revolves around pharmacokinetics/pharmacodynamics ( $\mathrm{Pk} / \mathrm{Pd}$ ) optimisation [55], regarding the inability to predetermine or influence the time frame between drug administration to patients and drug uptake by the haematophagous vectors in relation to the drug half-life, as well as the quantity of blood imbibed by the mosquitoes in relation to the volume of blood needed for effective drug action. Characterisation of the parasite- or vector-expressed surface molecules may also allow the 
isolation of potential transmission-blocking vaccine candidates [56]. The feasibility of this approach in curtailing transmission of mosquito-borne pathogens has been underpinned by the recent impressive progress made towards developing TBVs against Plasmodium parasites in their Anopheles vectors [57-59]. Altogether, TBD and TBV strategies will surpass the classical insecticide-based vector control, as they are not subject to selective pressure towards mosquito resistance [58]. Moreover, these strategies will be especially advantageous if conserved targets that exhibit broad-spectrum activity among different mosquito or parasite species or strains could be characterised, eliminating the need to develop targets for each mosquito-filaria combination.

Engineering of mosquitoes through transgenic technologies has become an increasingly emerging, mating-based control approach aimed at suppressing or modifying target vector populations in nature. Various methods employed in the current research activities are majorly based on sterile insect techniques (SITs) and gene drive systems [60-62]. SITs are self-limiting techniques that involve breeding and releasing of modified sterile males into the target area to mate with the wild females, and such mating results in the production of non-viable offspring [60]. Although the release of irradiated sterile male mosquitoes was recently tested in Sudan [63], Italy [64], and Indonesia [65], and showed encouraging performances, the recombinant DNA-based RIDL (release of insects carrying a dominant lethal gene) system $[60,61,66]$, a spin-off of SIT, has been most successful and rapidly spreading in field trials. The most obvious evidence is the release of the transgenic OX513A strain of Ae. aegypti in the Caribbean [67,68], Malaysia [69] and Brazil [70], with encouraging outcomes towards suppressing target wild populations. In fact, after critical risk assessment, release of the OX513A strain was approved by the Brazilian National Technical Commission on Biosafety and will probably be executed nationwide in the near future [71]. An offshoot of the RIDL technique is also currently pursuing the production of flightless females in Ae. aegypti progeny [72,73], and experimental studies are likewise being undertaken using Ae. albopictus (Skuse) [74] and An. stephensi (Liston) [75].

The invasive, self-sustaining gene drive systems use selfish genetic elements to integrate and spread desired traits in a target mosquito species, either for the purpose of replacing existing wild mosquito populations with strains or species that are incapable of pathogen transmission by incorporating anti-pathogen effector genes into the vectors (modification strategy), or for the purpose of reducing or eliminating natural vector populations by driving detrimental genes into the populations (suppression strategy) $[60,62,76]$. The discovery of naturally-occurring selfish genetic elements, such as HEGs (homing endonuclease genes), the heritable Wolbachia pipientis (Hertig), and MEDEA (maternal effect dominant embryonic arrest), and the mechanisms of their activity, inspired the development of synthetic gene drive systems that have now become the major focus of the current research $[60,62,76]$. The new synthetic CRISPR/Cas9 (clustered regularly-interspaced short palindromic repeats/CRISPR associated protein 9) system overcomes many of the shortcomings of previous synthetic gene drives and is rapidly gaining ground in vector-borne disease research applications [62,76]. The natural genetic factors controlling mosquito resistance to filarial parasites can provide the basis for population modification strategies by delivering designed antifilarial RNA or peptide effector into mosquitoes through CRISPR/Cas9 using tissue-specific promoters [76], while introgression of desirable suppression genotypes into wild mosquito populations can also be executed by delivering Cas9/sgRNA (single guide RNA) complexes through embryo injection [62]. As with the antifilarial mosquito population modification, delivery of effector molecules into the thoracic flight muscles appears more attractive as the flight muscle-specific promoters have been identified [53,77], and the thoracic flight muscles provide the longest parasite exposure time to effector molecules, while the absorption of the molecules by the parasites may also be aided by cuticular lysis/turnover during moulting and protein uptake via the parasite gut [76]. Essential secreted proteins at the vector-parasite interface, such as those controlling neuromuscular activities and migratory behaviours, are potential targets for developing peptide effectors, whereas the functionally-characterised Bmcpl-1 will serve in RNA effector applications [53,76]. 
The vast majority of current research activities towards the suppression of natural mosquito populations are being undertaken in the field of mosquito-borne viruses such as dengue, and in malaria control. However, a paramount benefit is the fact that mosquitoes acting as vectors for these diseases are also competent vectors of LF. Therefore, breakthroughs in these fields of research and eventual licensed application of the transgenic approaches on a global scale will have an immense synergistic effect in suppressing LF transmission, especially in areas where target mosquito species act as the major vector for LF or where the target mosquito-borne disease co-exists with LF. Moreover, particular species of transgenic mosquitoes can be released in LF-endemic areas even when other mosquito-borne diseases are not present.

\section{Conclusions}

The current speed in the war against mosquito-transmitted diseases is moving with an increasing energy. It is, however, clear that mosquito-filaria research has not been extensively explored, perhaps because some well-developed and advanced toolkits are still not in use. For instance, there are still indications that the genetic factors influencing mosquito resistance or susceptibility to filarial parasites have not been fully probed, but achieving this will require harnessing more advanced techniques and technologies [76]. Moreover, much remains to be done in the specific functional analysis of genes and proteins expressed in the intramosquito filarial stages. The quest to better understand these cardinal building blocks coordinating filarial parasites' adaptation, survival, development, and other physiological activities within the vector will unveil hidden 'golden nuggets' required to design novel transmission-blocking chemotherapeutics, vaccines, and potent effector molecules for transgenic mosquito applications. Transgenic mosquito technologies have become a powerful tool for propelling vector control research in designing novel control methods with promising effectiveness; nevertheless, to gainfully utilize the potential of these emerging hi-tech control strategies, an effective dialogue with the public and the stakeholders, as well as resolving issues regarding the licensed deployment of engineered mosquitoes in nature, is crucial [78-80]. Overall, considerable progress has been made in the global control of LF, but achieving the projected elimination target is now clearly uncertain. To maintain the gains of the current drug-based, vaccine-lacking control approaches and the hoped effectiveness of the new MDA recommendations, co-implementation of the budding vector control and transmission-blocking concepts is essential for a synergistic control approach that will not only speed up LF elimination but also augment the potential for its future eradication.

Acknowledgments: The author thanks Officer Adewale Adeniyi of the Nigerian Customs Service (NCS) for his financial assistance.

Author Contributions: D.O.F. undertook all the duties of authorship of this paper.

Conflicts of Interest: The author declares no conflict of interest.

\section{References}

1. Tolle, M.A. Mosquito-borne diseases. Curr. Probl. Pediatr. Adolesc. Health Care 2009, 4, 97-104. [CrossRef] [PubMed]

2. World Health Organization. A Global Brief of Vector-Borne Diseases; World Health Organization: Geneva, Switzerland, 2014.

3. World Health Organization. Lymphatic Filariasis: A Handbook of Practical Entomology for National Lymphatic Filariasis Elimination Programmes; World Health Organization: Geneva, Switzerland, 2013.

4. Chakraborty, S.; Gurusamy, M.; Zawieja, D.C.; Muthuchamy, M. Lymphatic filariasis: Perspectives on lymphatic filarial disease pathogenesis. Microcirculation 2013, 20, 349-364. [CrossRef] [PubMed]

5. Dreyer, G.; Noroes, J.; Addiss, D. The silent burden of sexual disability associated with lymphatic filariasis. Acta Trop. 1997, 63, 57-60. [CrossRef]

6. Ton, T.G.N.; Mackenzie, C.; Molyneux, D.H. The burden of mental health in lymphatic filariasis. Infect. Dis. Poverty 2015, 4, 34-41. [CrossRef] [PubMed] 
7. Obindo, J.; Abdulmalik, J.; Nwefoh, E.; Agbir, M.; Nwoga, C.; Armiya'u, A.; Davou, F.; Maigida, K.; Otache, E.; Ebiloma, A.; et al. Prevalence of depression and associated clinical and socio-demographic factors in people living with lymphatic filariasis in Plateau State, Nigeria. PLoS Negl. Trop. Dis. 2017, 11, e0005567. [CrossRef] [PubMed]

8. Ichimori, K.; King, J.D.; Engels, D.; Yajima, A.; Mikhailov, A.; Lammie, P.; Ottesen, E.A. Global programme to eliminate lymphatic filariasis: The processes underlying programme success. PLoS Negl. Trop. Dis. 2014, 8, e3328. [CrossRef] [PubMed]

9. World Health Organization. Essential Medicines Donated to Control, Eliminate and Eradicate Neglected Tropical Diseases; World Health Organization: Geneva, Switzerland, 2017.

10. World Health Organization. Guideline: Alternative Mass Drug Administration Regimens to Eliminate Lymphatic Filariasis; World Health organization: Geneva, Switzerland, 2017.

11. World Health Organization. Global programme to eliminate lymphatic filariasis: Progress report 2014. Wkly. Epidemiol. Rec. 2015, 90, 489-504.

12. Ramaiah, K.D.; Ottesen, E.A. Progress and impact of 13 years of the global programme to eliminate lymphatic filariasis on reducing the burden of filarial disease. PLoS Negl. Trop. Dis. 2014, 8, e3319. [CrossRef] [PubMed]

13. World Health Organization. Global Health Estimates Summary Tables. DALYs by Cause, Age and Sex, by WHO Region, 2000-2015; World Health Organization: Geneva, Switzerland, 2016.

14. World Health Organization. Global programme to eliminate lymphatic filariasis: Progress report 2015. Wkly. Epidemiol. Rec. 2016, 91, 441-460.

15. World Health Organization. Global programme to eliminate lymphatic filariasis: Progress report, 2016. Wkly. Epidemiol. Rec. 2017, 92, 594-607.

16. Melrose, W.D. Chemotherapy for lymphatic filariasis: Progress but not perfection. Expert Rev. Anti-Infect.Ther. 2004, 1, 571-577. [CrossRef]

17. McNulty, S.N.; Mitreva, M.; Weil, G.J.; Fischer, P.U. Inter and intra-specific diversity of parasites that cause lymphatic filariasis. Infect. Genet. Evol. 2013, 14, 137-146. [CrossRef] [PubMed]

18. Schwab, A.E.; Boakye, D.A.; Kyelem, D.; Prichard, R.K. Detection of benzimidazole resistance-associated mutations in the filarial nematode Wuchereria bacrofti and evidence for selection by albendazole and ivermectin combination treatment. Am. J. Trop. Med. Hyg. 2005, 73, 234-238. [PubMed]

19. Schwab, A.E.; Churcher, T.S.; Schwab, A.J.; Basáñez, M.G.; Prichard, R.K. Population genetics of concurrent selection with albendazole and ivermectin or diethylcarbamazine on the possible spread of albendazole resistance in Wuchereria bancrofti. Parasitology 2006, 133, 598-601. [CrossRef] [PubMed]

20. Wiwanitkit, V. Beta-tubulin isotype 1 conferred benzimidazole-resistance in lymphatic filariasis: An explanation by molecular concern. J. Blood Lymph 2017, 7, 1000123. [CrossRef]

21. McGreevy, P.B.; Bryan, J.H.; Oothuman, P.; Kolstrup, N. The lethal effects of the cibarial and pharyngeal armatures of mosquitoes on microfilariae. Trans. R. Soc. Trop. Med. Hyg. 1978, 72, 361-368. [CrossRef]

22. Bartholomay, L.; Christensen, B. Vector-parasite interactions in mosquito-borne filariasis. In The Filaria (World Class Parasites); Springer: Boston, MA, USA, 2002; Volume 5, pp. 9-19.

23. Paily, K.P.; Hoti, S.L.; Das, P.K. A review of the complexity of biology of lymphatic filarial parasites. J. Parasit. Dis. 2009, 33, 3-12. [CrossRef] [PubMed]

24. Hillyer, J.F. Mosquito immunity. Adv. Exp. Med. Biol. 2010, 708, 218-238. [CrossRef]

25. Beerntsen, B.T.; James, A.A.; Christensen, B.M. Genetics of mosquito vector competence. Microbiol. Mol. Biol. Rev. 2000, 64, 115-137. [CrossRef] [PubMed]

26. Beckett, E.B.; Boothroyd, B. Mode of nutrition of the larvae of the filarial nematode Brugia pahangi. Parasitology 1970, 60, 21-26. [CrossRef] [PubMed]

27. Kan, S.P.; Ho, B.C. Development of Brugia pahangi in the flight muscles of Aedes togoi: Ultrastructural changes in the infected muscle fibers and the infecting filarial larvae. Am. J. Trop. Med. Hyg. 1973, 22, 179-188. [CrossRef] [PubMed]

28. Lehane, M.J.; Laurence, B.R. Flight muscle ultrastructure of susceptible and refractory mosquitoes parasitized by larval Brugia pahangi. Parasitology 1977, 74, 87-92. [CrossRef] [PubMed]

29. Chen, C.C.; Shih, C.M. Exsheathment of microfilariae of Brugia pahangi in the susceptible and refractory strains of Aedes aegypti. Ann. Trop. Med. Parasitol. 1988, 82, 201-206. [CrossRef] [PubMed] 
30. Bennuru, S.; Meng, Z.; Ribeiro, J.M.; Semnani, R.T.; Ghedin, E.; Chan, K.; Lucas, D.A.; Veenstra, T.D.; Nutman, T.B. Stage-specific proteomic expression patterns of the human lymphatic filarial parasite Brugia malayi and its endosymbiont Wolbachia. Proc. Natl. Acad. Sci. USA 2011, 108, 9649-9654. [CrossRef] [PubMed]

31. Choi, Y.-J.; Ghedin, E.; Berrimen, M.; McQuillan, J.; Holroyd, N.; Mayhew, G.F.; Christensen, B.M.; Michalski, M.L. A deep sequencing approach to comparatively analyze the transcriptome of lifecycle stages of the filarial worm, Brugia malayi. PLoS Negl. Trop. Dis. 2011, 5, e1409. [CrossRef] [PubMed]

32. Li, B.; Wang, Z.; Rush, A.C.; Mitreva, M.; Weil, G.J. Transcription profiling reveals stage- and function-dependent expression patterns in the filarial nematode Brugia malayi. BMC Genom. 2012, 13, 184. [CrossRef] [PubMed]

33. Adebayo, J.M.; Geoffrey, N.G.; McManus, D.P. Serine protease inhibitors of parasitic helminths. Parasitology 2012, 139, 681-695. [CrossRef]

34. Fuhrman, J.A.; Piessens, W.F. Chitin synthesis and sheath morphogenesis in Brugia malayi microfilariae. Mol. Biochem. Parasitol. 1985, 17, 93-104. [CrossRef]

35. Fuhrman, J.A.; Lee, J.; Dalamagas, D. Structure and function of a family of chitinase isozymes from brugian microfilariae. Exp. Parasitol. 1995, 80, 672-680. [CrossRef] [PubMed]

36. Guiliano, D.B.; Hong, X.; McKerrow, J.H.; Blaxter, M.L.; Oksov, Y.; Liu, J.; Ghedin, E.; Lustigman, S. A gene family of cathepsin L-like proteases of filarial nematodes are associated with larval molting and cuticle and eggshell remodeling. Mol. Biochem. Parasitol. 2004, 136, 227-242. [CrossRef] [PubMed]

37. Wu, Y.; Preston, G.; Bianco, A.E. Chitinase is stored and secreted from the inner body of microfilariae and has a role in exsheathment in the parasitic nematode Brugia malayi. Mol. Biochem. Parasitol. 2008, 161, 55-62. [CrossRef] [PubMed]

38. Razin, S.V.; Borunova, W.; Maksimenko, O.G.; Kantidze, O.L. Cys2His2 zinc finger protein family: Classification, function, and major members. Biochem. Biokhimiiâ 2012, 77, 217-226. [CrossRef] [PubMed]

39. Choi, Y.-J.; Aliota, M.T.; Mayhew, G.F.; Erickson, S.M.; Christensen, B.M. Dual RNA-seq of parasite and host reveals gene expression dynamics during filarial worm-mosquito interactions. PLoS Negl. Trop. Dis. 2014, 8, e2905. [CrossRef] [PubMed]

40. Macdonald, W.W. The genetic basis of susceptibility to infection with semi-periodic Brugia malayi in Aedes aegypti. Ann. Trop. Med. Parasitol. 1962, 56, 373-382. [CrossRef]

41. Macdonald, W.W. The influence of the gene $f^{m}$ (filarial susceptibility, Brugia malayi) on the susceptibility of Aedes aegypti to seven strains of Brugia, Wuchereria and Dirofilaria. Ann. Trop. Med. Parasitol. 1965, 59, 64-73. [CrossRef] [PubMed]

42. Severson, D.W.; Mori, A.; Zhang, Y.; Christensen, B.M. Chromosomal mapping of two loci affecting filarial worm susceptibility in Aedes aegypti. Insect Mol. Biol. 1994, 3, 67-72. [CrossRef] [PubMed]

43. Beerntsen, B.T.; Severson, D.W.; Klinkhammer, J.A.; Kassner, V.A.; Christensen, B.M. Aedes aegypti: A quantitative trait locus (QTL) influencing filarial worm intensity is linked to QTL for susceptibility to other mosquito-borne pathogens. Exp. Parasitol. 1995, 81, 355-362. [CrossRef] [PubMed]

44. Juneja, P.; Osei-Poku, J.; Ho, Y.S.; Ariani, C.V.; Palmer, W.J.; Pain, A.; Jiggins, F.M. Assembly of the genome of the disease vector Aedes aegypti onto a genetic linkage map allows mapping of genes affecting disease transmission. PLoS Negl. Trop. Dis. 2014, 8, e2652. [CrossRef] [PubMed]

45. Juneja, P.; Ariana, C.V.; Ho, Y.S.; Akorli, J.; Palmer, W.J.; Pain, A.; Jiggins, F.M. Exome and transcriptome sequencing of Aedes aegypti identifies a locus that confers resistance to Brugia malayi and alters the immune response. PLoS Pathog. 2015, 11, e1004765. [CrossRef] [PubMed]

46. Megalhaes, T.; Oliveira, I.F.; Melo-Santos, M.A.; Oliveira, C.M.; Lima, C.A.; Ayres, C.F. Expression of defensin, cecropin, and transferrin in Aedes aegypti (Diptera: Culicidae) infected with Wuchereria bancrofti (Spirurida: Onchocercidae), and the abnormal development of nematodes in mosquito. Exp. Parasitol. 2008, 120, 364-371. [CrossRef] [PubMed]

47. Aliota, M.T.; Fuchs, J.F.; Rocheleau, T.A.; Clark, A.K.; Hillyer, J.F.; Chen, C.-C.; Christensen, B.M. Mosquito transcriptome profiles and filarial worm susceptibility in Armigeres subalbatus. PLoS Negl. Trop. Dis. 2010, 4, e666. [CrossRef] [PubMed]

48. Kumar, B.A.; Paily, K.P. Up-regulation of lipophorin (Lp) and lipophorin receptor (LpR) gene in the mosquito, Culex quinquefasciatus (Diptera: Culicidae), infected with the filarial parasite, Wuchereria bancrofti (Spirurida: Onchocercidae). Parasitol. Res. 2011, 108, 377. [CrossRef] [PubMed] 
49. Dhawan, R.; Gupta, K.; Kajla, M.; Kakani, P.; Choudhury, T.P.; Kumar, S.; Kumar, V.; Gupta, L. Apolipohorin-III acts as a positive regulator of Plasmodium development in Anopheles stephensi. Front. Physiol. 2017, 8, 185. [CrossRef] [PubMed]

50. Zdybicka-Barabas, A.; Cytryńska, M. Apolipophorins and insect immune response. Invertebr. Surviv. J. 2013, 10, 58-68.

51. Rono, M.K.; Whitten, M.M.A.; Oulad-Abdelghani, M.; Levashina, E.A.; Marios, E. The major yolk protein vitellogenin interferes with the anti-Plasmodium response in the malaria mosquito Anopheles gambiae. PLoS Biol. 2010, 8, e1000434. [CrossRef] [PubMed]

52. Tzertzinis, G.; Egaña, A.L.; Palli, S.B.; Robinson-Rechavi, M.; Gissendanner, C.R.; Liu, C.; Unnasch, T.R.; Maina, C.V. Molecular evidence for a functional ecdysone signaling system in Brugia malayi. PLoS Negl. Trop. Dis. 2010, 4, e625. [CrossRef] [PubMed]

53. Song, C.; Gallup, J.M.; Day, T.A.; Bartholomay, L.C.; Kimber, M.J. Development of an in vivo RNAi protocol to investigate gene function in the filarial nematode, Brugia malayi. PLoS Pathog. 2010, 6, e1001239. [CrossRef] [PubMed]

54. Sangshetti, J.N.; Shinde, D.B.; Kulkarni, A.; Arote, R. Two decades of antifilarial drug discovery: A review. RSC Adv. 2017, 7, 20628-20666. [CrossRef]

55. Sinden, R.E. Developing transmission-blocking strategies for malaria control. PLoS Pathog. 2017, 13, e1006336. [CrossRef] [PubMed]

56. Coutinho-Abreu, I.V.; Ramalho-Ortigao, M. Transmission blocking vaccines to control insect-borne diseases-A review. Mem. Inst. Oswaldo Cruz 2010, 105, 1-12. [CrossRef] [PubMed]

57. World Health Organization. Global Malaria Vaccine Pipeline; World Health Organization: Geneva, Switzerland, 2014.

58. Gonçalves, D.; Hunziker, P. Transmission-blocking strategies: The road map from laboratory bench to the community. Malar. J. 2016, 15, 95. [CrossRef] [PubMed]

59. Sauerwein, R.W.; Bousema, T. Transmission blocking malaria vaccines: Assays and candidates in clinical development. Vaccine 2015, 33, 7476-7482. [CrossRef] [PubMed]

60. Alphey, L. Genetic control of mosquitoes. Annu. Rev. Entomol. 2014, 59, 205-224. [CrossRef] [PubMed]

61. Gabrieli, P.; Smidler, A.; Catteruccia, F. Engineering the control of mosquito-borne infectious diseases. Genome Biol. 2014, 15, 535. [CrossRef] [PubMed]

62. Macias, V.M.; Ohm, J.R.; Rasgon, J.L. Gene drive for mosquito control: Where did it come from and where are we headed? Int. J. Environ. Res. Public Health 2017, 14, 1006. [CrossRef] [PubMed]

63. Ageep, T.B.; Damiens, D.; Alsharif, B.; Ahmed, A.; Salih, E.H.O.; Diabaté, A.; Lees, R.S.; Gilles, J.R.L.; El Sayed, B.B. Participation of irradiated Anopheles arabiensis males in swarms following field release in Sudan. Malar. J. 2014, 13, 484. [CrossRef] [PubMed]

64. Bellini, R.; Medici, A.; Puggioli, A.; Balestrino, F.; Carrieri, M. Pilot field trials with Aedes albopictus irradiated sterile males in Italian urban areas. J. Med. Entomol. 2013, 50, 317-325. [CrossRef] [PubMed]

65. Nurhayati, S.; Yunianto, B.; Ramadhani, T.; Ikawati, B.; Santoso, B.; Rahayu, A. Controlling Aedes aegypti population as DHF vector with radiation based-sterile insect technique in Banjarnegara Regency, Central Java. Indones. J. Nucl. Sci. Technol. 2013, 14,1-10. [CrossRef]

66. Wilke, A.B.B.; Gomes, A.D.; Natal, D.; Marrelli, M.T. Control of vector populations using genetically modified mosquitoes. Rev. Saúde Pública 2009, 43, 1-5. [CrossRef]

67. Harris, A.F.; Nimmo, D.; McKemey, A.R.; Kelly, N.; Scaife, S.; Donelly, C.A.; Beech, C.; Petrie, W.D.; Alphey, L. Field performance of engineered male mosquitoes. Nat. Biotechnol. 2011, 29, 1034-1037. [CrossRef] [PubMed]

68. Harris, A.F.; McKemey, A.R.; Nimmo, D.; Curtis, Z.; Black, I.; Morgan, S.A.; Oviedo, M.N.; Lacroix, R.; Naish, N.; Morrison, N.I.; et al. Successful suppression of a field mosquito population by sustained release of engineered male mosquitoes. Nat. Biotechnol. 2012, 30, 828-830. [CrossRef] [PubMed]

69. Lacroix, R.; McKemey, A.R.; Raduan, N.; Wee, L.K.; Ming, W.H.; Ney, T.G.; Rahidah, A.A.S.; Salman, S.; Subramaniam, S.; Nordin, O.; et al. Open field release of genetically engineered sterile male Aedes aegypti in Malaysia. PLoS ONE 2012, 7, e42771. [CrossRef] [PubMed]

70. Carvalho, D.O.; McKemey, A.R.; Garziera, L.; Lacroix, R.; Donnelly, C.A.; Alphey, L.; Malavasi, A.; Capurro, M.L. Suppression of a field population of Aedes aegypti in Brazil by sustained release of transgenic male mosquitoes. PLoS Negl. Trop. Dis. 2015, 9, e0003864. [CrossRef] [PubMed] 
71. De Andrade, P.P.; Aragão, F.J.L.; Colli, W.; Dellagostin, O.A.; Finardi-Filho, F.; Hirata, M.H.; Lira-Neto, A.C.; de Melo, M.A.; Nepomuceno, A.L.; da Nóbrega, F.G.; et al. Use of transgenic Aedes aegypti in Brazil: Risk perception and assessment. Bull. World Health Organ. 2016, 94, 766-771. [CrossRef] [PubMed]

72. Fu, G.; Lees, R.S.; Nimmo, D.; Aw, D.; Jin, L.; Gray, P.; Berendonk, T.U.; White-Cooper, H.; Scaife, S.; Phuc, H.K.; et al. Female-specific flightless phenotype for mosquito control. Proc. Natl. Acad. Sci. USA 2010, 107, 4550-4554. [CrossRef] [PubMed]

73. Facchinelli, L.; Valerio, L.; Ramsey, J.M.; Gould, F.; Walsh, R.K.; Bond, G.; Robert, M.A.; Lloyd, A.L.; James, A.A.; Alphey, L.; et al. Field cage studies and progressive evaluation of genetically-engineered mosquitoes. PLoS Negl. Trop. Dis. 2013, 7, e2001. [CrossRef] [PubMed]

74. Labbé, G.M.C.; Scaife, S.; Morgan, S.A.; Curtis, Z.H.; Alphey, L. Female-specific flightless (fsRIDL) phenotype for control of Aedes albopictus. PLoS Negl. Trop. Dis. 2012, 6, e1724. [CrossRef] [PubMed]

75. Marinotti, O.; Jasinskiene, N.; Fazekas, A.; Scaife, S.; Fu, G.; Mattingly, S.T.; Chow, K.; Brown, D.M.; Alphey, L.; James, A.A. Development of a population suppression strain of the human malaria vector mosquito, Anopheles stephensi. Malar. J. 2013, 12, 142. [CrossRef] [PubMed]

76. Zamanian, M.; Andersen, E.C. Prospects and challenges of CRISPR/Cas genome editing for the study and control of neglected vector-borne nematode diseases. FEBS J. 2016, 283, 3204-3221. [CrossRef] [PubMed]

77. Allen, M.L.; Christensen, B.M. Flight muscle-specific expression of act88F: GFP in transgenic Culex quinquefasciatus Say (Diptera: Culicidae). Parasitol. Int. 2004, 53, 307-314. [CrossRef] [PubMed]

78. Ernst, K.C.; Haenchen, S.; Dickinson, K.; Doyle, M.S.; Walker, K.; Monaghan, A.J.; Hayden, M.H. Awareness and support of release of genetically modified 'sterile' mosquitoes, Key West, Florida, USA. Emerg. Infect. Dis. 2015, 21, 320-324. [CrossRef] [PubMed]

79. Adalja, A.; Sell, T.K.; McGinty, M.; Boddie, C. Genetically modified (GM) mosquito use to reduce mosquito-transmitted disease in the US: A community opinion survey. PLoS Curr. Outbreaks 2016, 1. [CrossRef] [PubMed]

80. Panjwani, A.; Wilson, A. What is stopping the use of genetically modified insects for disease control? PLoS Pathog. 2016, 12, e1005830. [CrossRef] [PubMed]

(C) 2018 by the author. Licensee MDPI, Basel, Switzerland. This article is an open access article distributed under the terms and conditions of the Creative Commons Attribution (CC BY) license (http:/ / creativecommons.org/licenses/by/4.0/). 